PERSPECTIVE

\title{
Multifixation campimetry on line: a perimeter for the detection of visual field loss using the internet
}

\section{B Damato, C Groenewald}

Br J Ophthalmol 2003;87:1296-1298

More widespread perimetry would improve opportunities for preventing visual handicap from ocular and intracranial diseases, some of which are life threatening. With internet access becoming more ubiquitous, the authors have developed multifixation campimetry on line, for qualified practitioners and lay individuals around the world, free of charge.

See end of article for authors' affiliations

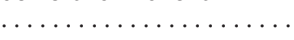

Correspondence to: Bertil Damato, PhD FRCOphth, St Paul's Eye Unit, Royal Liverpool University Hospital, Prescot Street, Liverpool L7 8XP, UK bertil@yamato.co.uk

Accepted for publication 25 February 2003
O ne of us (BD) previously developed various methods of "oculo-kinetic perimetry (OKP)." ${ }^{1-5}$ We describe this test, with two examples.

\section{TECHNIQUE AND CASE REPORTS}

Our website at http://www.testvision.org describes field loss and defines the purpose of the test, emphasising that it is: (1) under evaluation; (2) not replacing established perimeters; (3) for experienced computer users; and (4) of low sensitivity, to prevent false positives. The patient is advised to cover one eye, wear appropriate correction, and keep the head straight and still. Written instructions, a movie, and an interactive rehearsal train the patient. Advice is given on finding the correct working distance.

Clicking the mouse over a "smiley" (that is, (i)) prompts the appearance of a black on white stimulus, subtending $0.43^{\circ}$ and lasting 0.2 seconds. When the cursor is moved into the stimulus area another smiley appears in this location and examination proceeds. Missed stimuli prompt the message: "You missed this spot. Click on it to continue" and an auditory signal stops the patient waiting further. The first two stimuli are sham, allowing the subject to settle into the test.

Forty two points in the central $24^{\circ}$ field occur along 12 meridians, at $30^{\circ}$ intervals, and at stimuli straddle the horizontal and vertical meridians to facilitate recognition of altitudinal and homonymous defects. Additional points are clustered near the horizontal meridians, demonstrating nasal steps, and at $4^{\circ}$, screening for maculopathy. Points $16^{\circ}$ nasally and temporally detect the physiological blind spot also confirming that the correct eye was tested.

Missed physiological blind spots prompt an error message at the end of the test. The field plot can be printed, saved, or emailed. A questionnaire includes a study number, allowing transfer eccentricities of $4^{\circ}, 12^{\circ}, 16^{\circ}, 20^{\circ}$, and $24^{\circ}$. The of results to the relevant investigator. Our software enables emailed data to be reconstructed into field plots for viewing on the investigators' computer. Subjects can provide their address if they welcome questions and comments. Results are analysable with any statistics package.

Users are advised to: (a) repeat the test if the blind spot is missed, with the head straight, at the correct distance, and looking at the cursor as it is clicked; (b) consider results abnormal only if reproducible; and (c) show abnormal results to their practitioner.

Figure 1 shows the plot obtained by a 41 year old teacher attending our hospital with glaucomatous visual field loss in the left eye, his only seeing eye. Both the Humphrey visual field analyser and multifixation campimetry show dense, superior, arcuate defects with a nasal step. The patient performed self examination using his home computer, without prior instruction. Figure 2 shows normal results obtained by a 60 year old man browsing the internet.

\section{COMMENT}

Our cases demonstrate that multifixation campimetry on line permits self examination by computer literate individuals. To our knowledge, such perimetry via the internet has not been reported previously.

Multifixation campimetry enables assessment of the $24^{\circ}$ field with a standard monitor viewed from the normal distance. It is more "user friendly" than conventional methods, which fail when patients cannot suppress the foveation reflex as stimuli are presented. Currently, our test aims to detect only unequivocal abnormality, minimising distressing false positive results. We are also evaluating tests using random symbols to enhance fixation and low contrast stimuli to increase sensitivity.

Multifixation campimetry free of charge on the internet may facilitate the detection and management of disease, when conventional perimetry is impractical, and therefore merits further study.

\section{Authors' affiliations}

B Damato, C Groenewald, St Paul's Eye Unit, Royal Liverpool University Hospital, Prescot Street, Liverpool L7 8XP, UK

Sponsored by: The Eye Tumour Research Fund, Royal Liverpool University Hospital.

The authors have no proprietary interest in any aspect of this report. 
A

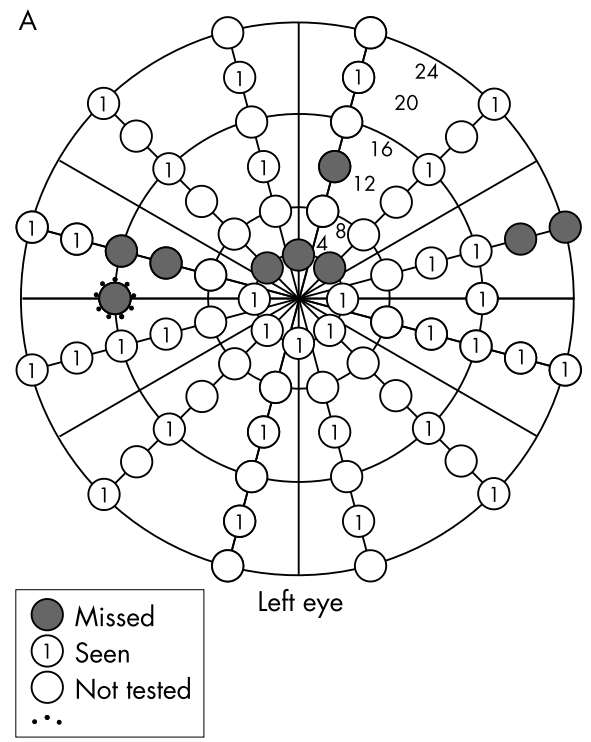

C

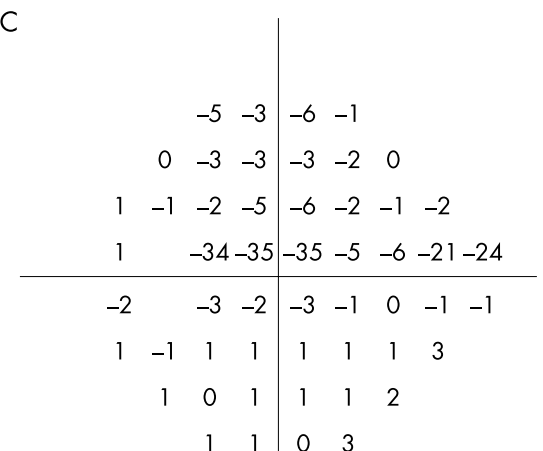

Total deviation

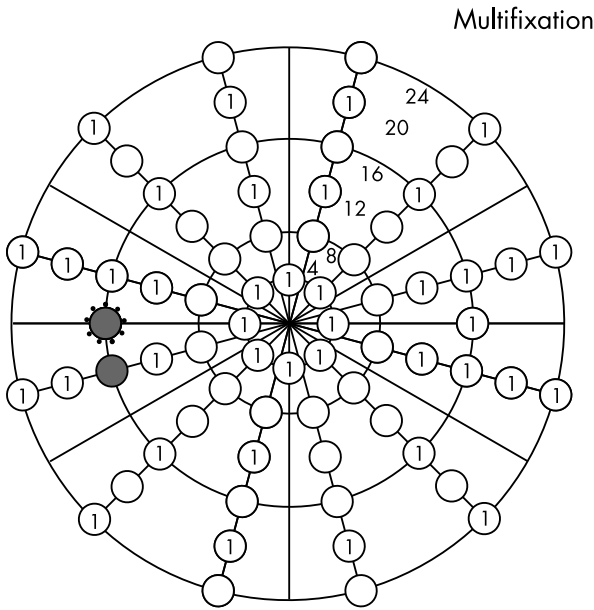

Left eye
B

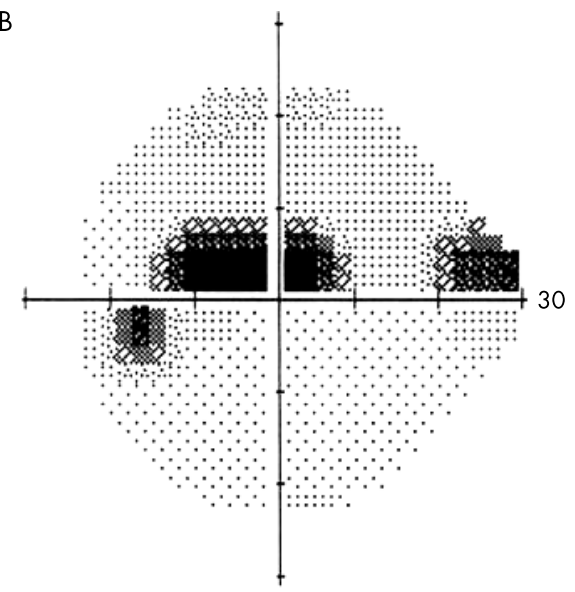

D

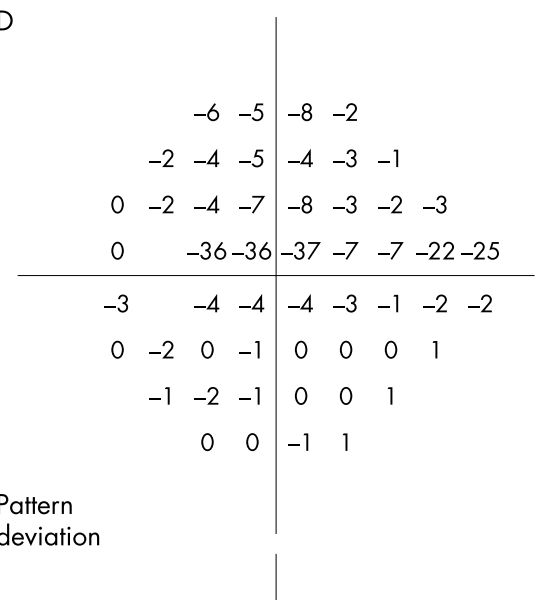

Figure 1 Visual field of the left eye of a 41 year old man showing a superior arcuate glaucomatous defect,

obtained by (A) self

examination using

multifixation campimetry on

line and (B) Humphrey visual

field analyser (HVFA). (C)

HVFA total deviation and (D)

HVFA pattern deviation.

Figure 2 Normal visual fields plotted with multifixation campimetry on line by a 60 year old male glaucoma suspect in the United States, who discovered the test while browsing the internet.

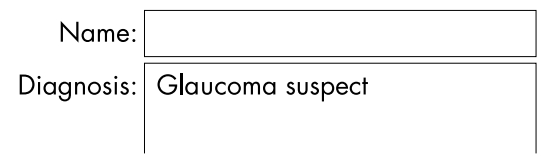

$\begin{array}{ll}\text { Age: } & 60 \text { years } \\ \text { Date: } & 31 / 12 / 2002\end{array}$ 


\section{REFERENCES}

1 Damato BE. Oculokinetic perimetry: a simple visual field test for use in the community. Br J Ophthalmol 1985;69:927-31.

2 Alvarez $\mathrm{E}$, Damato $\mathrm{BE}$, Jay JL, et al. Comparative evaluation of oculo-kinetic perimetry and conventional perimetry in glaucoma. $\mathrm{Br} J$ Ophthalmol 1988;72:258-62.
3 Alvarez E, Damato BE, Wakakura $M$ et al Oculo-kinetic perimetry. A visual field test for neuro-ophthalmic patients. Neuro-ophthalmol 1988;8:23-30.

4 Yamada N, Chen PP, Mills RP, et al. Screening for glaucoma with frequencydoubling technology and Damato campimetry. Arch Ophthalmol 1999;117:1479-84.

5 Johnston SC, Damato BE, Evans AL, et al. Computerised visual field test for children using multiple moving fixation targets. Med Biol Eng Comput 1989;27:612-16. 